\title{
Priority Research Areas to Accelerate the Development of Practical Ultra- conductive Copper Conductors
}

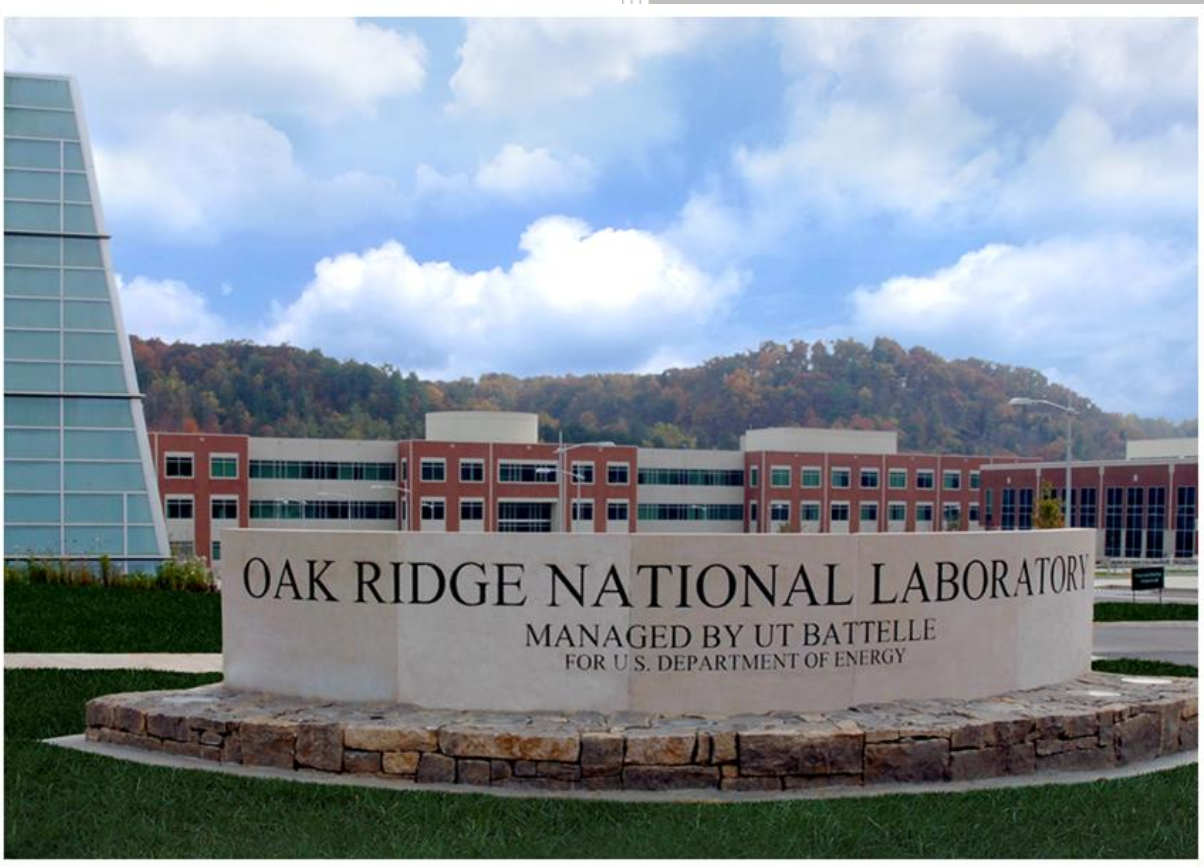

\section{Approved for public release:} Distribution is unlimited
Dominic F. Lee, Oak Ridge National Laboratory Malcolm Burwell and H. Stillman, International Copper Association

September 2015 


\section{DOCUMENT AVAILABILITY}

Reports produced after January 1, 1996, are generally available free via US Department of Energy (DOE) SciTech Connect.

Website http://www.osti.gov/scitech/

Reports produced before January 1,1996, may be purchased by members of the public from the following source:

National Technical Information Service

5285 Port Royal Road

Springfield, VA 22161

Telephone 703-605-6000 (1-800-553-6847)

TDD 703-487-4639

Fax 703-605-6900

E-mail info@ntis.gov

Website http://www.ntis.gov/help/ordermethods.aspx

Reports are available to DOE employees, DOE contractors, Energy Technology Data Exchange representatives, and International Nuclear Information System representatives from the following source:

Office of Scientific and Technical Information

PO Box 62

Oak Ridge, TN 37831

Telephone 865-576-8401

Fax 865-576-5728

E-mail reports@osti.gov

Website http://www.osti.gov/contact.html

This report was prepared as an account of work sponsored by an agency of the United States Government. Neither the United States Government nor any agency thereof, nor any of their employees, makes any warranty, express or implied, or assumes any legal liability or responsibility for the accuracy, completeness, or usefulness of any information, apparatus, product, or process disclosed, or represents that its use would not infringe privately owned rights. Reference herein to any specific commercial product, process, or service by trade name, trademark, manufacturer, or otherwise, does not necessarily constitute or imply its endorsement, recommendation, or favoring by the United States Government or any agency thereof. The views and opinions of authors expressed herein do not necessarily state or reflect those of the United States Government or any agency thereof. 
Electrical and Electronics Systems Research Division

\title{
PRIORITY RESEARCH AREAS TO ACCELERATE THE DEVELOPMENT OF PRACTICAL ULTRACONDUCTIVE COPPER CONDUCTORS
}

\author{
Dominic F. Lee - Oak Ridge National Laboratory \\ Malcolm Burwell and H. Stillman - International Copper Association
}

Date Published: September 2015

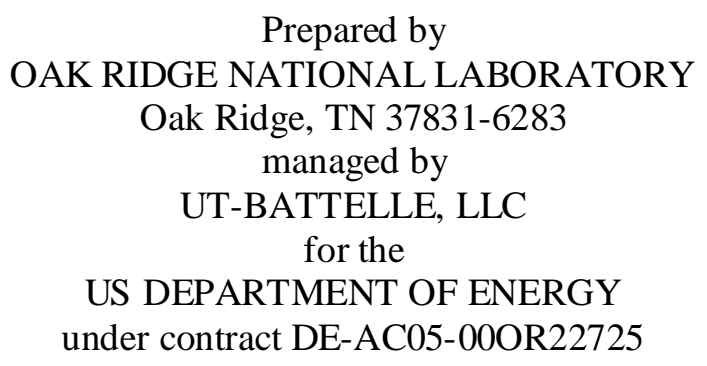





\section{CONTENTS}

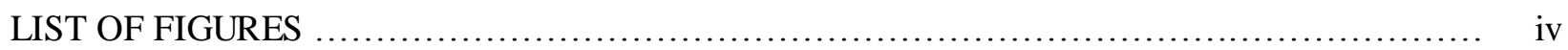

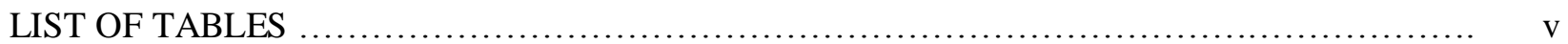

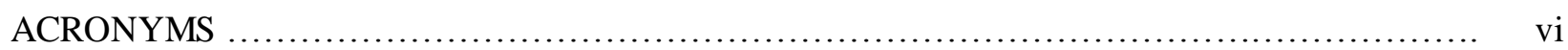

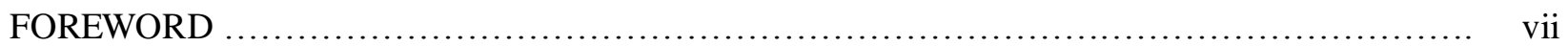

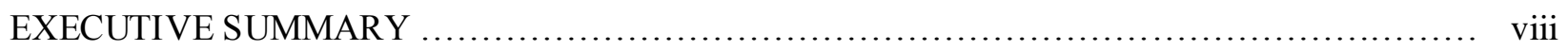

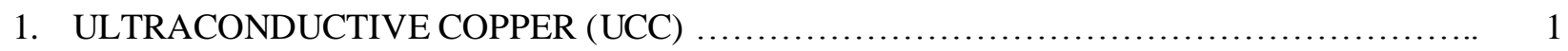

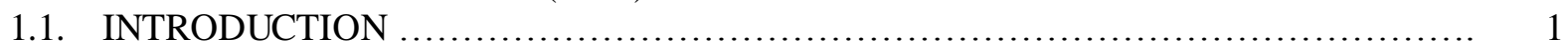

1.2. BRIEF DESCRIPTION OF CARBON NANOTUBES .............................. 2

1.3. THE CASE FOR ULTRACONDUCTIVE COPPER ................................ 2

1.4. MANUFACTURING APPROACHES FOR ULTRACONDUCTIVE COPPER .......... 4

1.4.1. Electrolytic Co-Deposition ................................................... 4

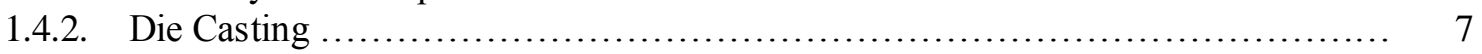

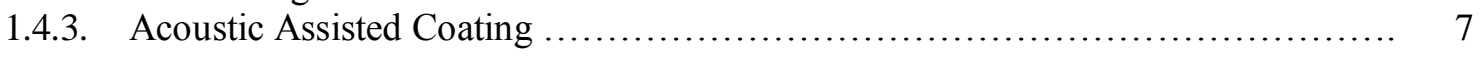

1.4.4. Surface Coating of CNTs for High Ampacity ........................................ 7

1.4.5. CNT Fiber Infiltration ................................................. 8

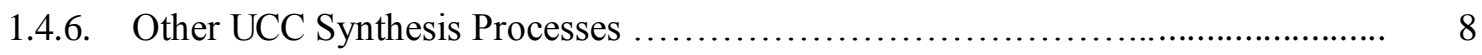

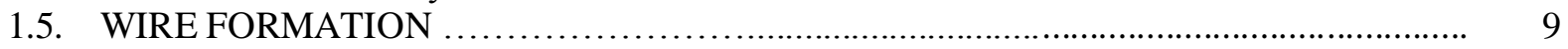

1.6. CHALLENGES FOR DEVELOPMENT AND COMMERCIALIZATION ............... 11

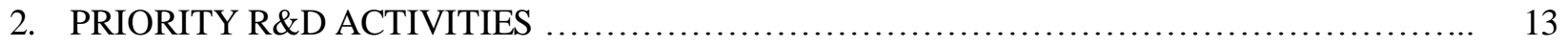

2.1. ULTRACONDUCTIVE COPPER STRATEGY MEETING ......................... 13

2.2. PRIORITY RESEARCH 1: MODELING OF ULTRACONDUCTIVE COPPER ......... 13

2.3. PRIORITY RESEARCH 2: STANDARDIZE MEASUREMENT PROTOCOLS .......... 16

2.4. PRIORITY RESEARCH 3: TECHNO-ECONOMIC ANALYSES ..................... 18

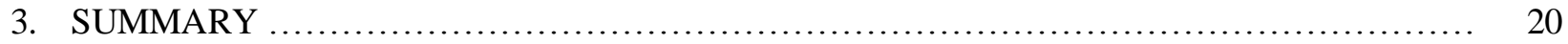

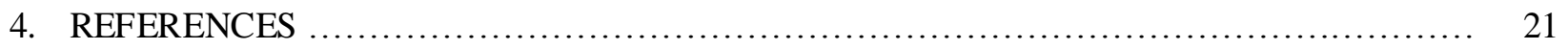

APPENDIX A. UCC STRATEGY MEETING LIST OF PARTICIPANTS ..................... 23 


\section{LIST OF FIGURES}

Fig. 1. Morphology of ultraconductive wire based on a copper/CNT composite ................ 1

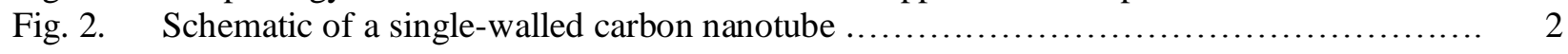

Fig. 3. Calculated resistivity for a composite of copper and single-walled nanotubes ............. 3

Fig. 4. Schematic drawing showing the electrolytic cell reported by Chen ..................... 4

Fig. 5. Other mechanical and physical properties reported by Chen $\ldots \ldots \ldots \ldots \ldots \ldots \ldots \ldots \ldots \ldots . \ldots \ldots$

Fig. 6. Electron micrograph of the surface of cryogenically-fractured UCC containing SWCNTs .................................................................... 6

Fig. 7. Schematic of "point electro co-deposition" for production of CNT reinforced copper

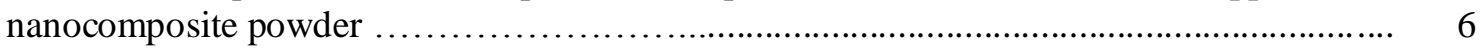

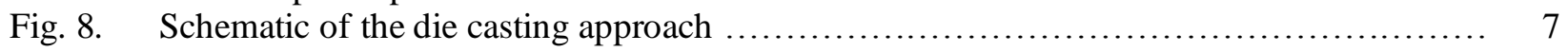

Fig. 9. Electrical performance of composite wires produced by the acoustic assisted coating

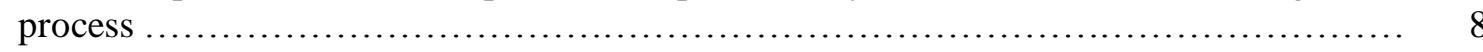

Fig. 10. Separation of nanocarbon from UCC on melting and re-solidification .................. 9

Fig. 11. Consolidation of UCC foil into a $16 \mathrm{~mm}$ diameter billet and hot extrusion into $2 \mathrm{~mm}$ diameter wire

Fig. 12. Cross-sections of $\mathrm{Fe} / \mathrm{Cu}-\mathrm{CNT}$ composite wire fabricated using fine copper powder with diameter less than $1 \mu \mathrm{m}$

Fig. 13. Schematic electric field - current density curves of a superconductor at different magnetic fields 


\section{LIST OF TABLES}

Table 1. Measured electrical resistivity of samples produced by Electrolytic Co-Deposition ........ 5

Table 2. List of important research activities nominated by attendees to the UCC Strategy

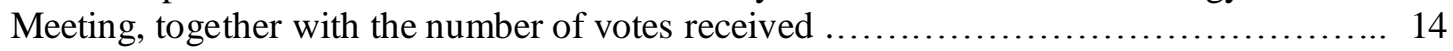

Table 3. 3M HTLS ACCR upgrade cost comparison example (project cost per line mile) .......... 19 


\section{ACRONYMS}

$\begin{array}{ll}\text { AC } & \text { alternating current } \\ \text { ACCC } & \text { aluminum conductor composite core } \\ \text { ACCR } & \text { aluminum conductor composite reinforced } \\ \text { ACSR } & \text { aluminum conductor steel reinforced } \\ \text { ACSS } & \text { aluminum conductor steel supported } \\ \text { CNT } & \text { carbon nanotube } \\ \text { CTE } & \text { coefficient of thermal expansion } \\ \text { DC } & \text { direct current } \\ \text { DWCNT } & \text { double-walled carbon nanotube } \\ \text { E } & \text { electric field } \\ \text { GNP } & \text { graphite nanoplatelet } \\ \text { HTLS } & \text { high temperature low sag } \\ \text { HTS } & \text { high temperature superconductor } \\ \text { I } & \text { electric current } \\ \text { ICA } & \text { International Copper Association } \\ \text { J } & \text { current density } \\ \text { MWCNT } & \text { multi-walled carbon nanotube } \\ \text { ORNL } & \text { Oak Ridge National Laboratory } \\ \text { SWCNT } & \text { single-walled carbon nanotube } \\ \text { UCC } & \text { ultraconductive copper } \\ \text { V } & \text { electric voltage } \\ \text { \%IACS } & \text { percent International Annealed Copper Standard } \\ \rho & \text { resistivity }\end{array}$




\section{FOREWORD}

This report documents the findings at an Ultraconductive Copper Strategy Meeting held on March 11, 2015 in Washington DC. The aim of this meeting was to bring together researchers of ultraconductive copper in the U.S. to identify and prioritize critical non-proprietary research activities that will enhance the understanding in the material and accelerate its development into practical conductors. Every effort has been made to ensure that the discussion and findings are accurately reported in this document.

Support was provided to the Oak Ridge National Laboratory by the U.S. Department of Energy Office of Electricity Delivery and Energy Reliability under contact number DE-AC05-00OR22725. 


\section{EXECUTIVE SUMMARY}

Ultraconductive copper is an emerging materials technology that can potentially transform the energy sector because of its promises of enhanced electrical conductivity, higher strength and better thermal management characteristics. Because of these attributes, stronger, smaller and lighter power equipment may be envisioned, ultimately leading to advances such as high capacity power lines, lighter electric vehicles, more powerful wind turbines, etc.

This novel material is a nanocomposite consisting of a copper metal matrix with carbon nanotubes as the secondary phase. Its improved transport and mechanical properties stem from the exceptional nature of carbon nanotubes, such as the occurrence of ballistic conductivity. Significant progress has been made worldwide in the development of this material, with tantalizing results of enhanced electrical and mechanical properties. Unfortunately, the present fabrication processes are unstable and these enticing results are frequently tempered by non-uniformity, unpredictability or non-reproducibility. These uncertainties, coupled with lack of understanding in what and how different factors will affect its performance as well as competing interests amongst researchers and developers combined to prevent the rapid development of the material into practical conductors.

In order to initiate the process to overcome these issues, an Ultraconductive Strategy Meeting was coorganized by Oak Ridge National Laboratory and the International Copper Association, and was held on March 11, 2015 in Washington DC. This meeting brought together active ultraconductive copper researchers in the U.S. and aimed to identify and prioritize non-proprietary research activities that will enhance the understanding of the material, accelerate its development and facilitate collaborations in noncompeting research. Many activities were suggested, and the following represents the top three consensus priority research activities for Agency support:

1) Modeling of UCC material to obtain foundational understanding in its operation. First principles modeling is the top priority research identified by the group. Many factors, from atomistic to macroscopic, may be included in the models to guide the development of the material. By extension, appropriate experimental efforts are needed to validate these models. This activity is needed to underpin and guide the current mostly experimental/practical UCC development work across the U.S.;

2) Develop standardized measurement protocols to assure validity and credibility of data.

The group advocates for the development of standardized measurement protocols such that results are not dependent on when or where they are measured. Protocols to be developed should include the measurement of physical, transport and morphological properties such as resistivity, ampacity, carbon nanotube distribution and alignment, etc. Round-robin testing of samples amongst researchers to identify discrepancies and deficiencies should be encouraged. Utilization of a reputable and neutral third party to verify the results from all stakeholders should be explored;

3) Perform techno-economic analyses to quantify value propositions and set performance targets for relevant applications.

The group recognizes that having an accurate estimation of potential impacts of the technology and quantitative value propositions for various relevant applications are essential to the research, development and commercialization of ultraconductive copper. Analyses should be performed to assess the cost, performance and benefits of the material as well as the entire component or system for each application. Performance targets can then be set to guide the development of the material for specific applications. Intangibles such as environmental impacts, public policies etc. should also be considered. 
While U.S. researchers have been leading the effort in developing ultraconductive copper, the achievement gap is rapidly diminishing due to increasing activities from competitors worldwide. For example, the European Commission FP7 program has invested €3.3 million in a consortium of 14 companies and universities with a cost share of an additional $€ 1.7$ million. This 3-year "Ultra Wire" project aims to develop the material to a level where pilot manufacturing can be planned. In order not to be left behind, concerted efforts should be made and resources need to be provided to perform these priority research activities in the U,S. 



\section{ULTRACONDUCTIVE COPPER (UCC)}

\subsection{INTRODUCTION}

Second only to silver, copper exhibits one of the lowest resistivities $\left(\rho=1.72 \times 10^{-8} \Omega-\mathrm{m}\right.$ at $\left.20^{\circ} \mathrm{C}\right)$ amongst all metals. Because of their low costs, copper and its cousin aluminum $\left(\rho=2.82 \times 10^{-8} \Omega-\mathrm{m}\right.$ at $20^{\circ} \mathrm{C}$ ) are the two metals used in most of the applications that require good electrical conduction. Even though they are excellent conductors, a portion of the electricity being carried is nevertheless lost as dissipated heat due to the finite resistivity. As such, considerable amount of savings can result if the conductivity of these metals can be improved. One potential way to accomplish this is through the incorporation of carbon nanotubes (CNTs) into a copper matrix forming a nanocomposite called Ultraconductive Copper (UCC) as seen in Fig. 1. Stemming from the unique electrical characteristics of CNT, sizable enhancements in conductivity [1-9] and ampacity [10] have been reported in laboratoryscaled UCC samples.

Unfortunately because of the enormous potential rewards, there are few publications that detail the progress and status of UCC in the open literature. Much research and development effort, however, is being pursued around the world, and occasional information can be glimpsed from published patents and applications as well as through personal contacts with disparate groups of UCC researchers and developers. What is known is that present UCC fabrication processes appear to be unstable, leading to non-uniform, unpredictable and non-reproducible results. Slow progress, then, will likely remain until concerted efforts can be made to overcome the common challenges.

a)

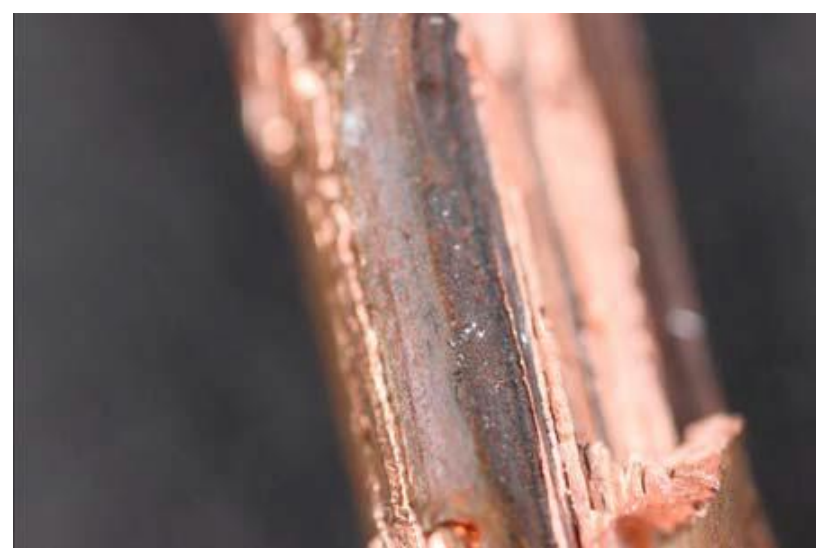

b)

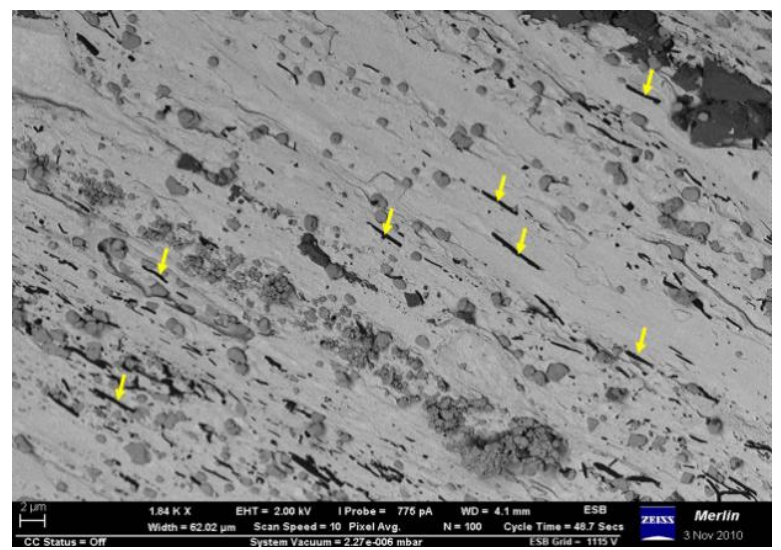

Fig. 1. Morphology of ultraconductive wire based on a copper/CNT composite. a) Longitudinally-sectioned wire showing regions of high (grey, axial) and low (copper colored near wire surface) electrical conductivity, and b) Electron-mic rograph taken in the high conductivity area of Fig. 1a displaying separated, dispersed and oriented CNTs (yellow arrows) embedded in the copper matrix. (Source: T. Nayfeh, A. Wiederholt at Cleveland State University). 


\subsection{BRIEF DESCRIPTION OF CARBON NANOTUBES}

Carbon is capable of forming different allotropes because of its valency. Examples include 1-D carbon nanotube, 2-D graphene sheet, 3-D buckminsterfullerene "bucky-ball", graphite and diamond. Carbon nanotubes have a hollow cylindrical nanostructure, with typical diameter ranging from 0.4 to $100 \mathrm{~nm}$ and lengths up to many millions times the diameter. Single-walled carbon nanotube (SWCNT) is formed by one-atom-thick sheet of graphene rolled into a seamless cylinder at specific and discrete angles (chirality) see Fig. 2. Similarly, multi-walled carbon nanotubes (MWCNT) can be visualized as multiple layers of graphene being rolled into cylinders.

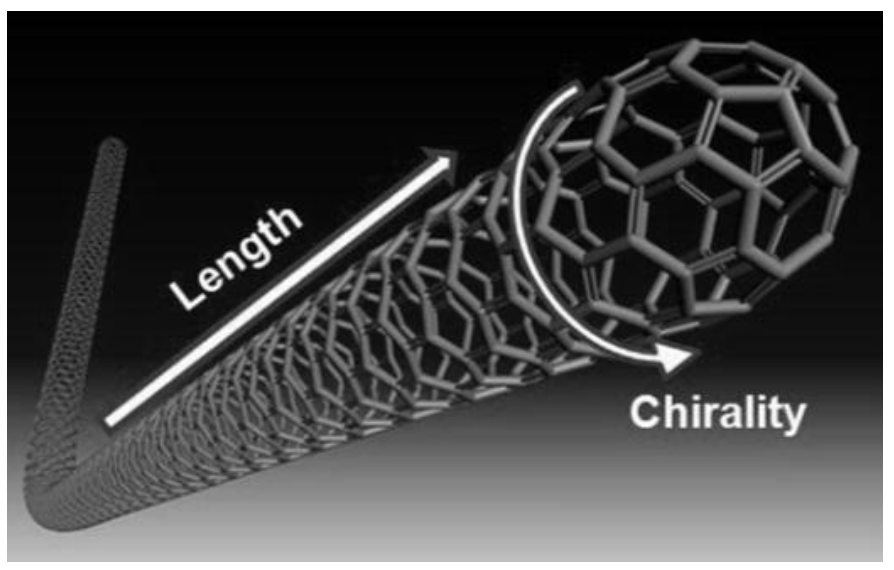

Fig. 2. Schematic of a single-walled carbon nanotube.

The unique nanostructure and $s p^{3}$ chemical bonds of CNT are theorized to impart many novel and superior properties to the material, including electrical, mechanical, thermal, electrochemical, optical, etc. Regarding electrical properties, which is the most important factor for the electricity sector, CNTs can behave like a metal or semiconductor depending on their chirality. In a normal metal, electrons flow through the metal and are scattered and slowed by impurities, defects and phonons, giving rise to electrical resistance. The average length an electron can travel freely before a collision that will change its momentum is called mean free path, which is characteristic of a material. The nano-scaled cross section of CNT, on the other hand, promotes electron propagation along its longitudinal axis, giving the material its one-dimensionality. Consequently, conduction in CNT is quantized and the maximum electrical conductance is equal to that of a ballistic quantum channel. When ballistically conducted, the electron mean free path is large and electrons travel along the CNT without being scattered. In this situation, the resistance of a CNT will be extremely low and is independent of its length. It is this unique behavior of CNTs that provides the potential for significant enhancement in electrical conductivity of UCC. At present, the exact mechanism of ballistic conduction in CNT is not fully understood. For SWCNTs, it has been suggested that electrons travel through a cloud of nonhybridized $\pi$-orbitals on the inner and outer tube surfaces as described by Luttinger-state transport models [11,12]. For MWCNTs, electrons may travel in the spaces between graphene layers. While there is the potential for very high conductance in CNTs, imperfections have been found to strongly influence the actual property because of their deleterious effects on the charge density distribution.

\subsection{THE CASE FOR ULTRACONDUCTIVE COPPER}

As previously mentioned, copper exhibits a high electrical conductivity of $5.8 \times 10^{7} \mathrm{~S} / \mathrm{m}$ at $20^{\circ} \mathrm{C}$ and is the standard to which conductivity of other materials are compared. This is accomplished through what is known as Percent International Annealed Copper Standard (\% IACS) ratio, which compares the electrical 
conductivity of a material to that of copper. For example, copper used for most electrical applications has an electrical conductivity of 100\% IACS whereas ultra-pure copper can attain a value as high as 103\% IACS. By comparison, ultra-pure aluminum has an electrical conductivity of $65 \%$ IACS, and UCC has the potential to push the conductivity to well above $100 \%$ IACS.

The concept of ultraconductive copper was first proposed by Hjortstam et al. in 2004 [1]. These researchers predicted that if aligned SWCNTs can be homogeneously distributed into a copper matrix, the electrical conductivity of the resulting nanocomposite may be more than doubled to that of pure copper. Based on a simple effective-medium model, their calculation that is reproduced in Fig. 3 suggests that the addition of SWCNTs will immediately reduce the resistivity to below that of copper of $1.72 \mu \Omega-\mathrm{cm}$. Moreover, aligned SWCNTs are more effective in decreasing the resistivity than randomly distributed CNTs. It can be seen from the figure that an estimated value of 30 to $40 \mathrm{vol} \%$ SWCNTs (4 to $6 \mathrm{wt} \%$ ) is sufficient to reduce the resistivity of the UCC to $0.86 \mu \Omega-\mathrm{cm}$ (represented by the horizontal dashed line), which is half that of copper or a conductivity of $200 \%$ IACS. Unpublished experimental results from NanoRidge Materials Inc., Cleveland State University and the University of Central Florida suggest that the actual wt.\% necessary to enhance conductivity to such a level may be an order of magnitude lower than that postulated by Hjortstam [1].

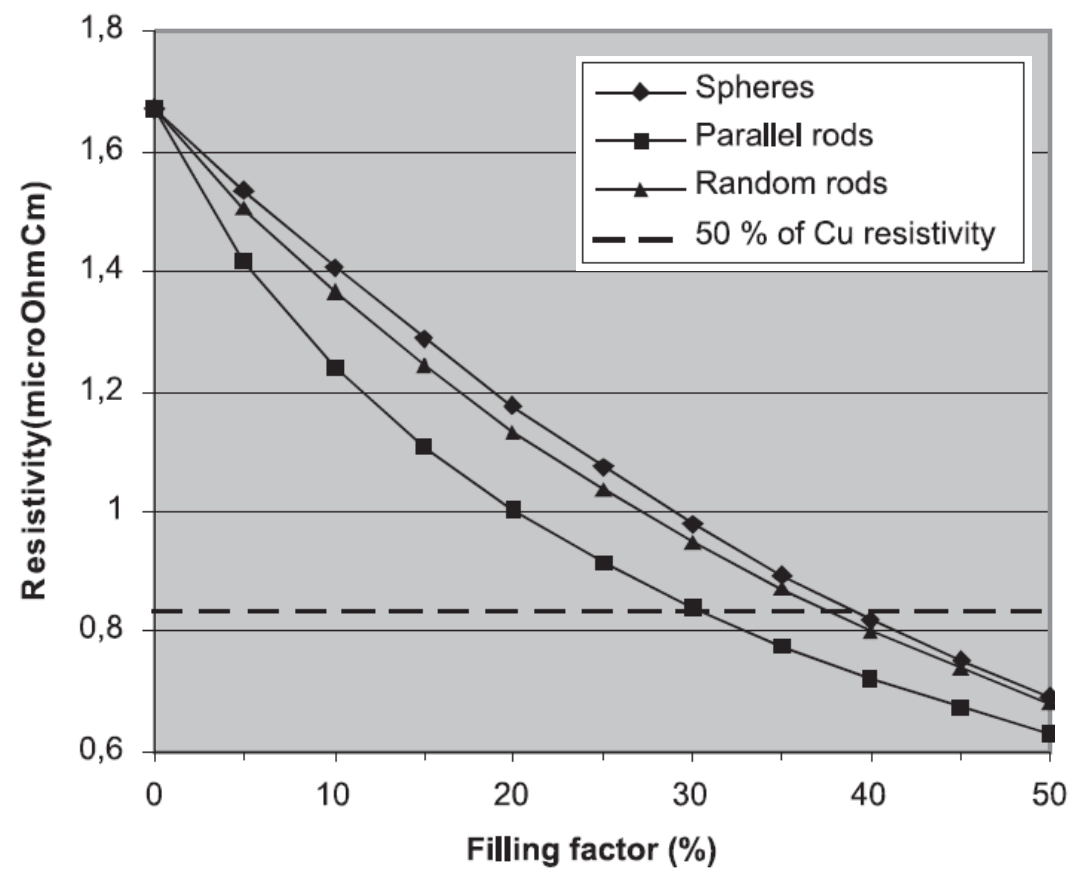

Fig. 3. Calculated resistivity for a composite of copper and singlewalled nanotubes. The resistivity is shown as a function of volume fraction of single walled carbon nanotubes (the filling factor) for three different geometries. The dashed horizontal line is a resistivity level that is $50 \%$ below the resistivity of copper at room temperature. [1].

In order to achieve success in UCC, the authors postulated the importance of the following three essential conditions: 1) high quality, non-deformed CNTs should be used, 2) methods to homogeneously disperse aligned CNTs should be developed, and 3) develop processing methods that will provide excellent electrical contacts between CNTs as well as between CNTs and copper. All these factors are seriously being considered in all the current UCC process development efforts. 


\subsection{MANUF ACTURING APPROACHES FOR ULTRACONDUCTIVE COPPER}

Several scalable approaches are presently being investigated around the world for the synthesis of UCC in ways that could lead to mass manufacturing. These production processes, however, are far from stable today and produce inconsistent results. All the following processes have demonstrated tantalizing smallscale laboratory sample results with conductivities $>130 \%$ IACS.

\subsubsection{Electrolytic Co-Deposition}

Several research teams are exploring various electrolytic co-deposition approaches to produce UCC. Electrolytic co-deposition is a method that has been successfully used to incorporate non-metallic particles into a metal matrix obtained from electrolytes containing the particles in a suspended state. In this method, second-phase particles are suspended in a metal ion electrolyte within a cell. The particles adsorb the positively charged metal ions and gain positive electric charge while they migrate to the cathode surface driven by electrostatic attraction and electrolyte convection forces. As the particles stick to the cathode surface and discharge, positive metal ions are deposited on the cathode surface around the particles, thereby incorporating the particles into the metallic deposit. Process parameters such as metal ion concentration, current density, electrolyte temperature and whether it is being agitated, presence of any additive, etc. have all been shown to affect the deposition rate and quality of the resulting composite.

Some details of a specific electrolytic co-deposition process were provided by Chen [2]. In that process, pre-treatment of the CNTs by surfactants such as cetyl trimethyl ammonium bromide or octyl trimethyl ammonium bromide positively charges the CNTs and keeps them dispersed within the electrolyte. As the copper ions within the solution are also positively charged, co-deposition of the copper and the CNTs occurs at the cathode of the electrolytic cell (Fig. 4). For the electrolyte solution, $\mathrm{CuSO}_{4}$ and $\mathrm{H}_{2} \mathrm{SO}_{4}$ have been successfully used as the metal ion source and the electrolyte source, respectively. Nano-composite deposition rate is controlled by varying the current density, achieving rates as low as $1 \mu \mathrm{m} / \mathrm{hr}$ to as high as $1 \mu \mathrm{m} / \mathrm{min}$. Table 1 shows the average electrical resistivity measured on a $22 \mu \mathrm{m}$-thick sample, indicating that the UCC has an electrical conductivity $41 \%$ higher than that of pure copper.

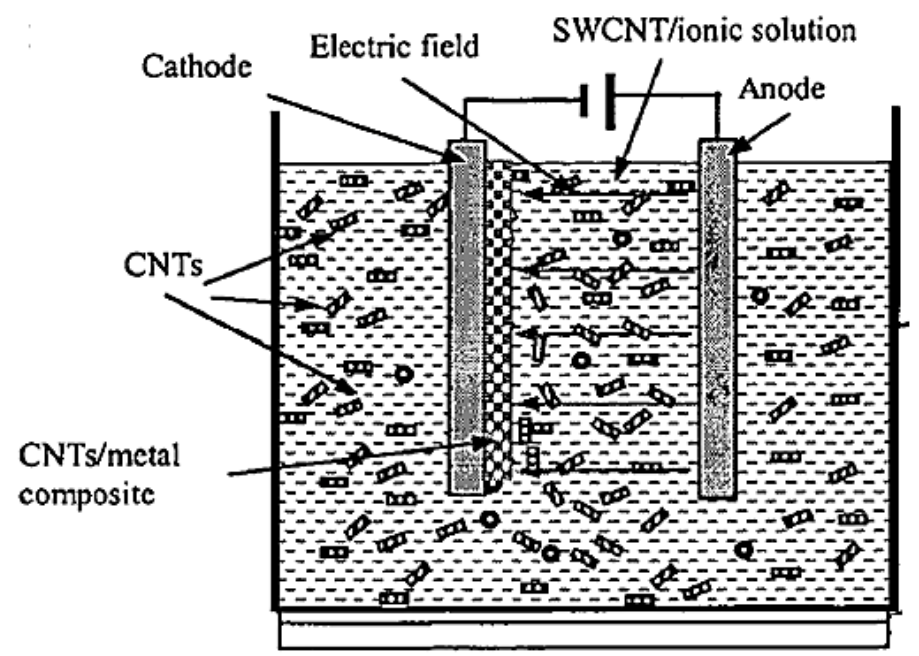

Fig. 4. Schematic drawing showing the electrolytic cell reported by Chen [2]. 
Table 1. Measured electrical resistivity of samples produced by Electrolytic Co-Deposition [2]

\begin{tabular}{|l|c|c|}
\hline Material Deposited & $\begin{array}{c}\text { Average } \\
\text { Electrical Resistivity } \\
(\mu \Omega-c m)\end{array}$ & $\begin{array}{c}\text { Average } \\
\text { Electrical Conductivity } \\
(\% \text { IACS })\end{array}$ \\
\hline $\begin{array}{l}\mathrm{Cu} / \mathrm{SWCNT} \text { composite } \\
(22 \mu \mathrm{m} \text {-thick })\end{array}$ & 1.22 & 141 \\
\hline $\begin{array}{l}\text { Pure copper } \\
(10.5 \mu \mathrm{m} \text {-thick })\end{array}$ & 1.72 & 100 \\
\hline
\end{tabular}

a)

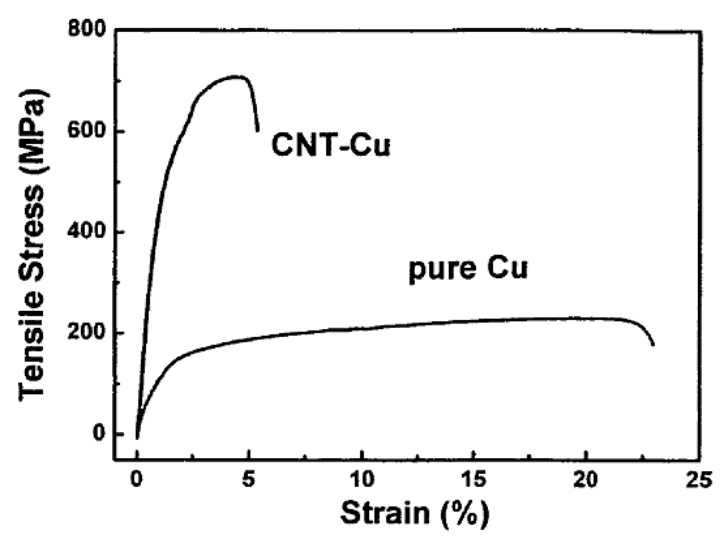

b)

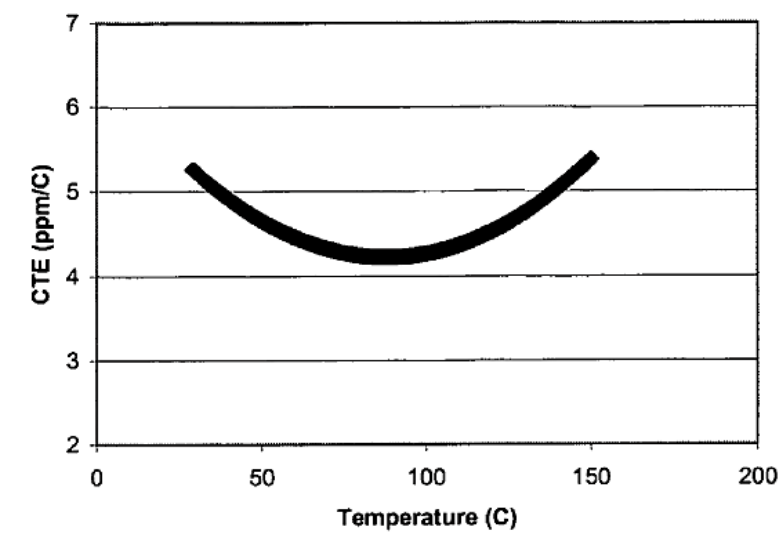

Fig. 5. Other mechanical and physical properties reported by Chen. a) Strength and ductility, b) Coefficient of thermal expansion. [2].

Figure 5a shows the stress-strain curves obtained from samples produced from that study. It can be seen from the figure that both the ultimate tensile strength and the stiffness of the UCC have been enhanced. Meanwhile, ductility of the nanocomposite is found to be lower than that of pure copper, indicating that the material will be more prone to brittle fracture. Coefficient of thermal expansion (CTE) of the UCC is shown in Fig. $5 \mathrm{~b}$ as a function of temperature. It can be seen that CTE of the UCC has a value ranging between 4 to $5.5 \times 10^{-6} /{ }^{\circ} \mathrm{C}$ (versus $17 \times 10^{-6} /{ }^{\circ} \mathrm{C}$ for pure copper). While Chen did not specify the exact percentage of CNTs in these samples, he did indicate that UCCs produced with SWCNTs had higher electrical conductivity and strength than those produced using MWCNTs.

In a parallel effort, NanoRidge Materials Inc., a U.S. company focusing on the commercialization of nanomaterials, is developing its electrolytic co-deposition process to produce an UCC product called TeraCopper® [3]. Figure 6 shows a scanning electron microscopy image of the fractured surface of an electrolytically-synthesized UCC wire. This surface was obtained by fracturing a $2 \mathrm{~mm}$-diameter UCC wire that had been cryogenically cooled. It is proposed that the deformation features seen on the fractured surface represent a map of the exposed SWCNTs. There is ongoing effort to better characterize the CNT distribution in these materials. Ampacities of the UCC wires have been characterized by NanoRidge, and selected samples have been tested by third party partner. Thus far, ampacity as high as $5.6 \times 10^{4} \mathrm{~A} / \mathrm{cm}^{2}$ has been reported for an UCC wire produced by NanoRidge, compared to a value of $3.9 \times 10^{4} \mathrm{~A} / \mathrm{cm}^{2}$ measured on a companion sample produced from $99.9 \%$ pure copper. This represents a $44 \%$ increase in the current carrying capacity and points to the potential of UCC in power equipment. 


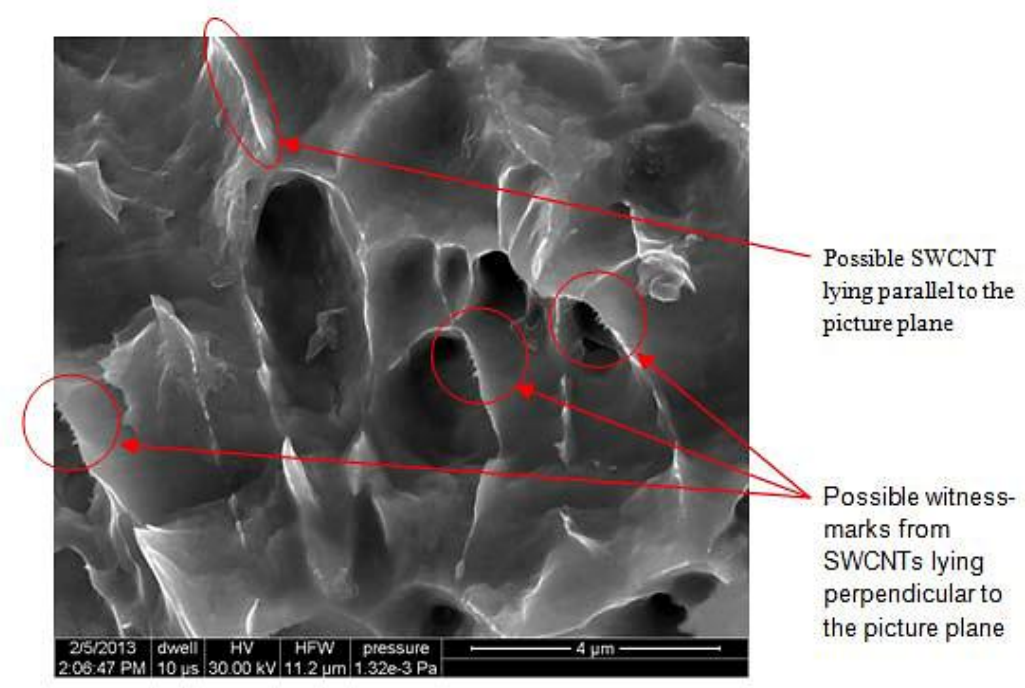

Fig. 6. Electron micrograph of the surface of cryo-genically-fractured UCC containing SWCNTs (Source: NanoRidge Materials Inc. - TeraCopper ${ }^{\circledR}$ material).

Electrodeposition processes are also being developed around the world to produce UCC powders [4]. Equipment and procedure used in this process are quite similar to those of the electrolytic co-deposition method described previously. Basically, CNTs are suspended in a copper ion-containing solution and a DC current is applied to the setup. The application of a high enough current density, however, resulted in weakly adhered UCC powder that can readily be sloughed off to the bottom of the cell and later harvested (Fig. 7). The electrolytic production of copper powders has been done since 1886 [13] and mass production is possible using continuous-flow deposition cells [14]. Similarly, production of UCC powders in this manner is straightforward. However, effective and cost-competitive means must be developed to consolidate the powder into UCC wires with required micro-/nano-structural characteristics without affecting the targeted performances. In addition, challenges associated with oxidation and porosity must be resolved.

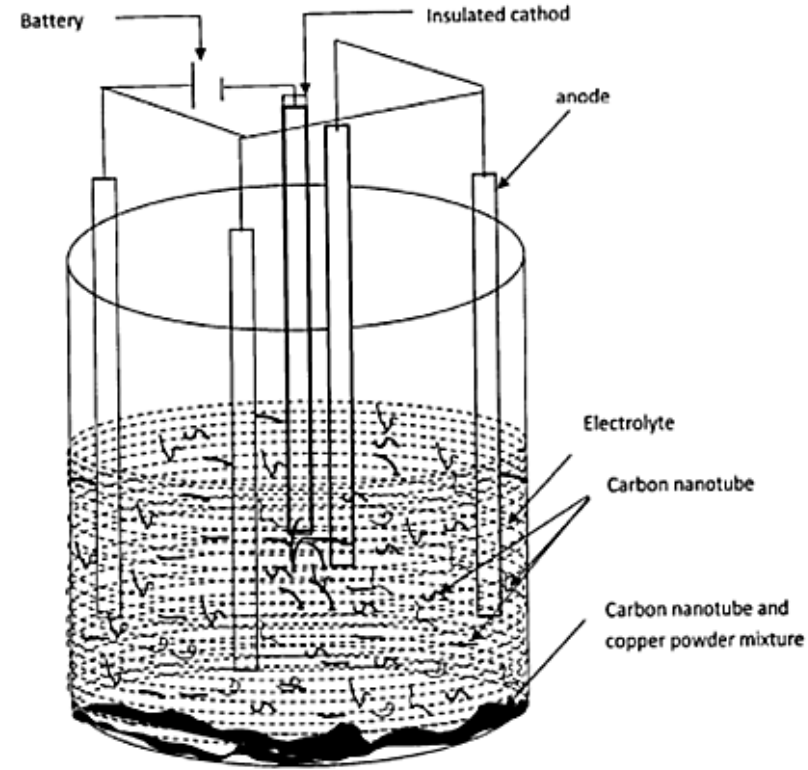

Fig. 7. Schematic of "point electro co-deposition" for production of CNT reinforced copper nanocomposite powder [4]. 


\subsubsection{Die Casting}

Die casting is an established approach to metal forming. Nayfeh et al. [5] have modified this approach to specifically produce UCCs with the required features. In their method, these researchers first pre-loaded CNTs into a cartridge before placing it into the shot sleeve of a cold chamber die casting machine (Fig. 8 ). This is followed by introducing liquid copper into the shot sleeve where mixing of the liquid metal and CNTs occurs. The mixture is then injected into a die and the composite is solidified. Three zones are defined in their casting system in order to mix and align the CNTs in the composite. In the first zone, liquid copper and CNTs are agitated to distribute the nanotubes within the mixture. In the second zone, the flow of liquid copper becomes laminar with the goal of aligning the CNTs along the axis of the casting. In the final zone, heat is extracted to solidify the mixture. UCC samples produced in such a manner have been reported to exhibit electrical conductivity of $113 \%$ IACS. To further develop the method and enhance the UCC performance, these researchers have proposed a further modification by including magnesium chloride (transformed to magnesium metal in a post-processing step) as an additive, with the goal of improving the CNT-copper interface. The rationale being that magnesium metal is known to wet CNT which copper does not, and it is soluble in copper. Therefore, this addition may form a tie layer between CNTs and copper such that good electrical transport between the CNTs and the copper matrix may be assured.

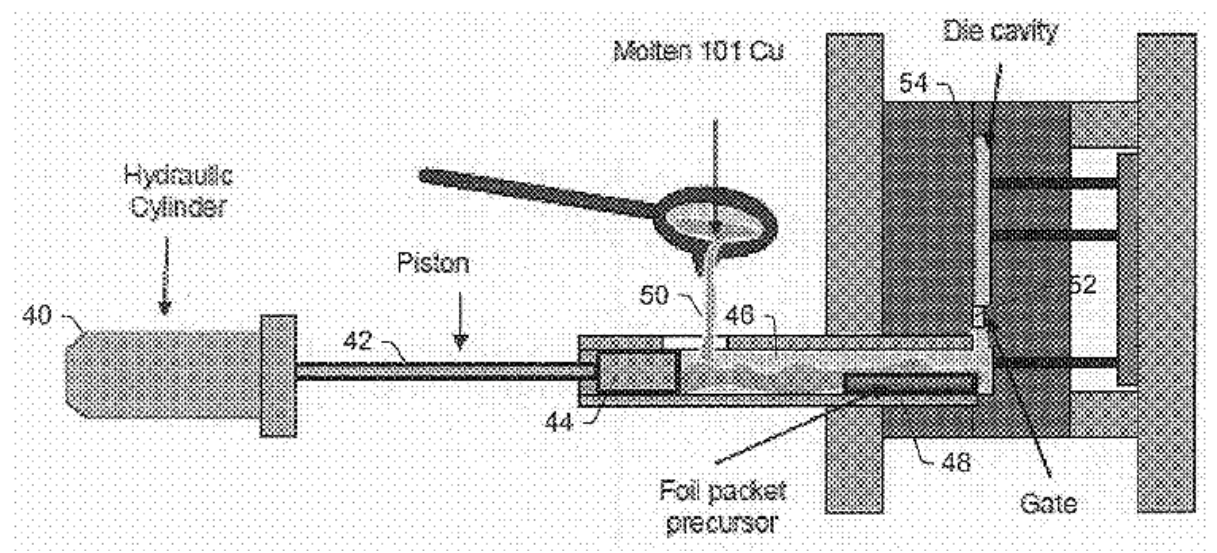

Fig. 8. Schematic of the die casting approach [5].

\subsubsection{Acoustic Assisted Coating}

Holesinger [6] has reported on an acoustically engineered resonant system that is capable of depositing high-quality coatings of CNTs onto the outside surface of copper wire substrates. In this process, a short copper wire is immersed into a tube containing CNTs that are suspended in a fluid. This is followed by applying an acoustic excitation in the vicinity of a high-order resonance that corresponds to concentric ring and nodal line formation along the central axis of the tube. The contents in the tube are thus agitated and concentrated near the central copper wire by repeatedly sweeping the excitation frequency near such resonance. This led to the formation of a high-conductivity and high-quality CNT coating on the copper wire. However, conductivity of greater than 100\% IACS has yet to be demonstrated in these wires (Fig. 9). Many challenges remain even if this approach is proven successful. These include continuous manufacturing, joining, coating adhesion, thermal shock, insulation, etc.

\subsubsection{Surface Coating of CNTs for High Ampacity}

Separately, researchers at NanoRidge have developed a process to coat, and then embed CNTs into the outer surface of a pure copper wire [30]. Early results have suggested that such bare wires show an 


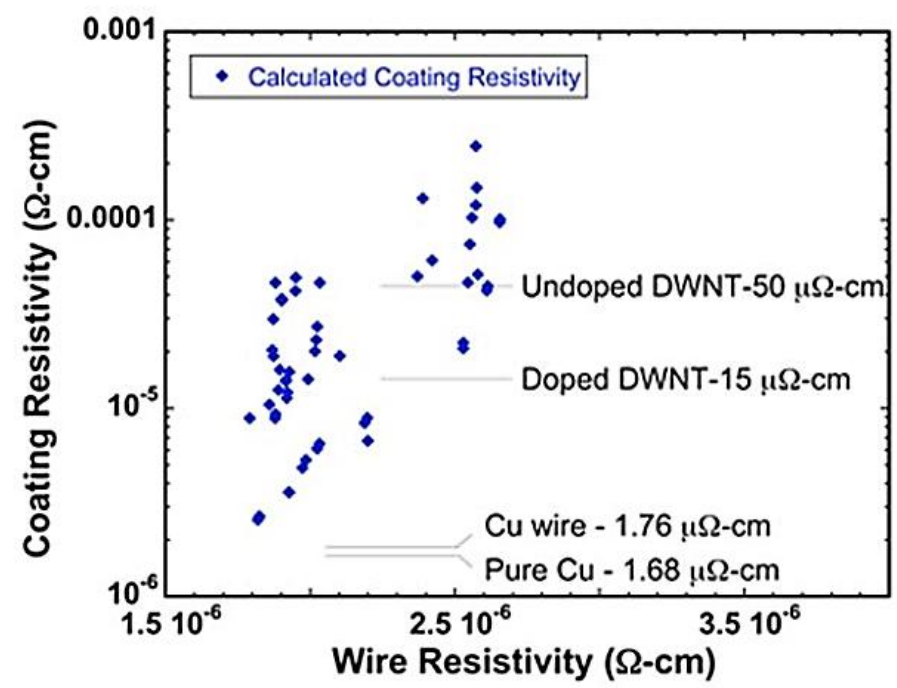

Fig. 9. Electrical performance of composite wires produced by the acoustic assisted coating process [6].

ampacity $>40 \%$ higher than the ampacity of bare pure copper wires. This work is at an early stage and is in the process of being validated by an independent third party. There is speculation that the higher ampacity is enabled by the increased heat transfer imparted to the wire by the CNT surface coating.

\subsubsection{CNT Fiber Infiltration}

Researchers at Cambridge University in the UK are exploring a novel way to produce continuous lengths of UCC nanocomposite. Carbon nanotubes are known to be able to form yarn-like CNT "fiber" bundles, where CNT-CNT connection is maintained by van der Waals (pi-stacking) forces. The CNTs within the yarn are thus pre-aligned. These researchers have already developed a procedure to form such yarns, and they intend to infiltrate these yarns with copper via vapor deposition or electrodeposition processes. This work is at an early stage, and UCC produced in such a manner has yet to be reported and enhanced properties demonstrated. Most recently, the European Commission awarded a €3.3 million FP7 development project (called "Ultrawire") [9] to a consortium of 14 companies and universities led by Cambridge. With a cost share of $€ 1.7$ million, this 3 -year project commenced in 2013 , and aims to develop the material to a level where pilot manufacturing can be planned.

\subsubsection{Other UCC Synthesis Processes}

Two other processes have been investigated for the formation of UCC. Neither has been successful thus far:

\section{Laser Formation}

This process employs a high pressure laser chemical deposition method where SWCNTs are built up by laser-induced breakdown of gas precursors, with simultaneous laser-induced cladding with metal [7]. It involves the growth of very long CNTs and the product is in the form of a continuous wire. Exceptional electrical conductivity of greater than $10,000 \%$ IACS has been claimed, but the result has not been verified. To the best of our knowledge, this effort has stopped because of the high research and estimated production costs.

\section{Powder Metallurgical Synthesis}

A number of researchers [15-17] have studied the efficacy of ball-milling of CNTs into the surface of copper particles, which is followed by consolidation using processes such as spark plasma sintering. None of these researchers has reported on samples with electrical conductivities greater than $100 \%$ IACS so far. 


\subsection{WIRE FORMATION}

Many of the processes that are being developed to produce UCCs result in materials that are not shaped for immediate usage in commercial applications, i.e. wires. For instance, electrolytic co-deposition produces UCC sheets or powder whereas die casting leads to short rods. In order to achieve broad market penetration, these UCCs must be formed into continuous wires of varying sizes. Therefore, considerations must be given to the development of appropriate wire forming processes.

Ideally, production of UCC wires would involve established processes such that existing equipment and knowledge could be brought to bear. Typically, wire forming begins with the continuous casting of liquid copper into rod, followed by (hot) extrusion and drawing into wires. This first step, however, may not be directly applicable to UCC because CNT inclusions may separate from the melt due to the differences in CNT and copper densities, resulting in inhomogeneous distribution of CNTs (Fig. 10). Recent efforts to examine means (e.g. high shear mixing of viscous mixture near the melting point of copper) to prevent this separation have not been successful [30].
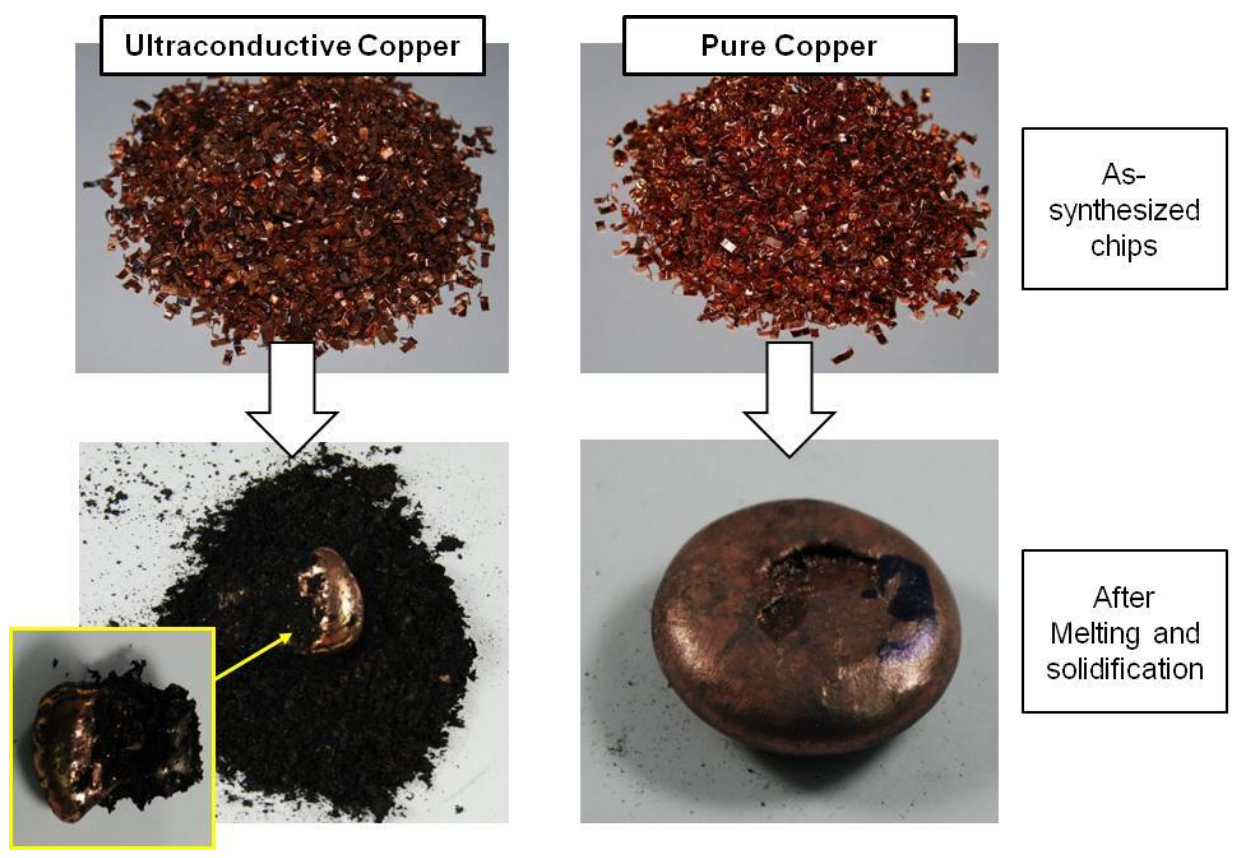

Fig. 10. Separation of nanocarbon from UCC on melting and re-solidification (Source: AGH University of Science and Technology, Krakow, Poland, material supplied by NanoRidge Materials Inc.).

In light of this limitation, alternatives to melt-processing are being investigated in which the material is formed through mechanical means where the UCC never reaches a molten state. Several approaches are described below. None of the processes has thus far achieved an electrical conductivity of greater than $100 \%$ IACS for more than very short lengths. Some unverified results have suggested greater than $200 \%$ IACS over 1-2 mm lengths and greater than $115 \%$ IACS over centimeter lengths.

The combination of mechanical consolidation and hot extrusion is presently being explored as a way to form UCC sheets into workable shapes before wire drawing. In this approach, the UCC is cold or hot pressed into a billet, which is then subjected to hot extrusion that is expected to align the CNTs along the extrusion direction (Fig. 11). Effort is ongoing to examine the degree of CNTs distribution and alignment and to further develop the process. 
a)

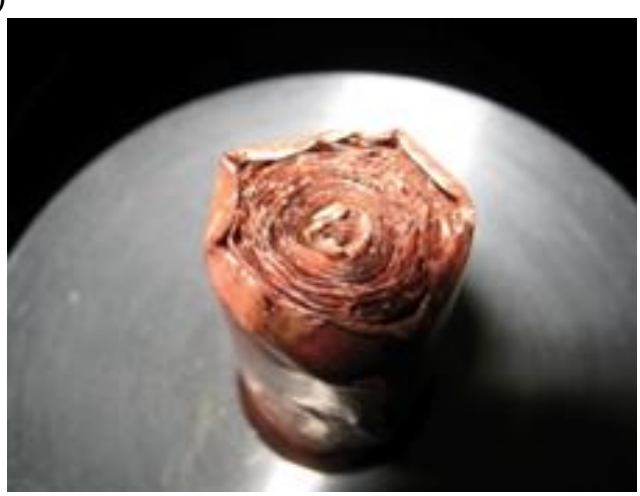

b)

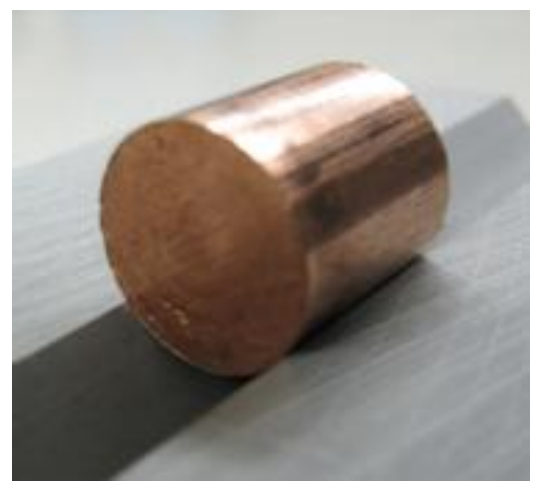

c)

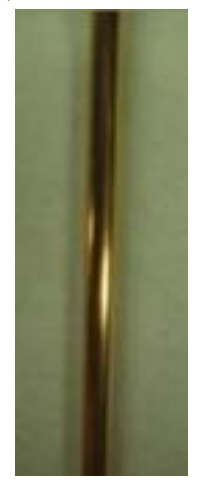

Fig. 11. Consolidation of UCC foil into a $16 \mathrm{~mm}$ diameter billet and hot extrusion into 2 mm diameter wire. a) before pressing, b) after pressing, c) after hot extrusion. (Source: Ohio University, material supplied by NanoRidge Materials Inc.).

Similarly, UCC that is originally produced as powders can be formed into workable shapes through the consolidation and extrusion process. Consolidation may be performed in a variety of ways including hotpressing, isotactic pressing, spark plasma sintering and direct powder extrusion [15]. One approach that is borrowed from the nano-ceramic extrusion industry [18] commences by introducing UCC powder in a copper can. The powder and can is then hot degassed in a vacuum and then sealed by electron beam welding. The sealed can together with the UCC powder contained therein are subsequently hot extruded into wire form within an inert atmosphere. Another variance involves loading UCC powder into a tube and the tube is compressed in a die to consolidate the powder (Fig. 12) [8].

Yet another way to produce UCC wire is by combining UCC synthesis together with wire forming into a single process. Attempts have long been made to directly deposit copper electrolytically into wire [19,20]. Although technically successful, the high process costs coupled with necessary post-processing steps make the method less commercially attractive. Questions remain whether this is a feasible way to produce UCC wires and whether the higher cost is competitive with other methods of UCC wire production. Finally, availability of CNT yarns [21] makes the method of wire formation through copper infiltration (mentioned in previous section) attractive. A major challenge is expected to be the extent to which copper can penetrate into the interior of the CNT fiber bundle.

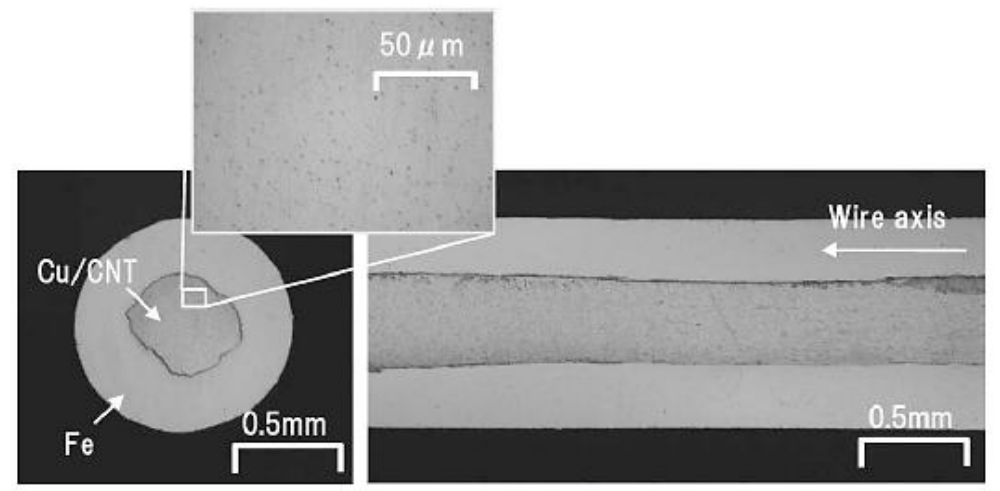

Fig. 12. Cross-sections of $\mathrm{Fe} / \mathrm{Cu}-\mathrm{CNT}$ composite wire fabricated using fine copper powder with diameter less than $1 \mu \mathrm{m}$. CNT is SWNT and mechanical alloying has been performed for 30 minutes before packing into an iron tube [8]. 


\subsection{CHALLENGES FOR DEVELOPMENT AND COMMERCIALIZATION}

Like any novel material, the main barriers to commercialization and broad market penetration of UCC are performance and cost. In terms of performance, ample laboratory results have shown the great promise of enhanced electrical conductivity and/or ampacity. However, the present fabrication processes are unstable, leading to performance non-uniformity, unpredictability and non-reproducibility. Clearly, commercial products cannot be made under these conditions. One major challenge to achieving consistent performance in UCC is the lack of understanding in how various factors affect the nanocomposite and its properties. Other challenges include little information from literature as well as the limited collaboration between researchers, compounded by the disparate nature of current research and characterization methodologies.

As for the cost barrier, manufacturing and materials costs are the main drivers. The challenge is to reduce these costs through innovative processing and economy-of-scale from mass-manufacturing. In terms of materials costs, although CNTs are the focus of research around the world, the prices of CNTs remain high. Recent data indicates that the pricing of MWCNTs is typically around $\$ 200$ to $\$ 1,000 / \mathrm{kg}$, and as high as $\$ 50,000$ to $\$ 100,000 / \mathrm{kg}$ for SWCNTs. Commoditization and scale up of CNT production is presently hampered by the lack of high-volume applications. As usage of CNTs increases in volume, it is anticipated that their costs will become closer to the raw material cost of other forms of carbon (eg. high quality graphite rods cost around $\$ 60 / \mathrm{kg}$ ). If CNTs could be produced at the cost of graphite, the combined raw material costs of UCC might approach $110 \%$ that of pure copper.

It is evident that there are a number of challenges to overcome before UCC will achieve widespread commercial acceptance. First, the fabrication process(es) need to be further developed and stabilized so that long lengths of UCC with uniform and predictable properties can be produced with little scrap. Second, the price and availability of CNTs must be reduced to a level where they can be incorporated into wire products produced at high volume. Finally, UCC wire-manufacturing costs will also need to be significantly lowered. 


\section{PRIORITY R\&D ACTIVITIES}

\subsection{ULTRACONDUCTIVE COPPER STRATEGY MEETING}

A significant amount of research is currently underway in the U.S. and around the world to develop processing techniques for bulk UCC materials. There are, however, several challenges that slow the rapid and efficient development of UCC from laboratory curiosities into practical conductors. These include performance inconsistencies, little to no collaboration between researchers, and insufficient information in open literature to validate the results. Most importantly, while there are tantalizing results that show substantial enhancement in electrical conductivity compared to that of pure copper, these results are typically non-uniform, unpredictable and non-repeatable. That is, conductivity is frequently location dependent, and varies significantly along the length of a sample. It is becoming clear that concentrating on process refinement alone will not address this inconsistency issue; R\&D activities that lead to foundational understanding on how UCC operates must be performed in order to achieve the degree of predictability and reliability that is necessary for commercial success.

In order to initiate the process that will address these issues, Oak Ridge National Laboratory (ORNL) and the International Copper Association (ICA) co-organized an UCC Strategy Meeting held on March 11, 2015 in Washington DC. The purpose of this meeting was to bring together active UCC stakeholders in the U.S. to identify research activities that will address the fundamental challenges to the successful development of UCC. The expected outcomes were consensus on the Top Three Priority Research Activities as well as improved collaboration between researchers based on this face-to-face contact. A list of participants is shown in Appendix A.

The UCC Strategy Meeting was structured to encourage free flowing of non-proprietary exchanges while maximizing the efficient usage of the limited time. As such, participants were invited to make a one page presentation on what they considered to be the top research activities that will accelerate the development of practical UCC. Armed with this information, the meeting moved on to round-the-table nomination of research activities, followed by polling and more in-depth discussion on the top three priorities as identified by the group. A list of the needed activities thus identified is shown in Table 2, together with the number of votes received. The ordering of activities in the table does not indicate any preference. Rather, these seemingly disparate activities are grouped into broad topical areas of Modeling, Factors that may impact the UCC performance, Experimental considerations, Testing, Processing, Value Proposition, Collaboration and Outreach. It is immediately evident that the three priority activities are:

1) Modeling of UCC material to obtain foundational understanding in its operation;

2) Develop standardized measurement protocols to assure validity and credibility of data;

3) Perform techno-economic analyses to quantify value propositions and set performance targets for relevant applications.

\subsection{Priority Research 1: Modeling of Ultraconductive Copper}

Modeling, specifically modeling from first principles, is the consensus top research identified by the group. Models are fundamental tools used to understand and predict the behaviors of materials and

phenomena. They facilitate the study of system response to changes in many variables and the factors that dominate such response without incurring the time and effort necessary to perform the full range of 
Table 2. List of important research activities nominated by attendees to the UCC Strategy Meeting, together with the number of votes received

\begin{tabular}{|c|c|c|}
\hline Activity & Votes & Topic \\
\hline $\begin{array}{l}\text { Modeling } \\
\text { Modelled Factors: } \\
\text { - Effects of CNT length } \\
\text { - Effects of CNT surface functionalization } \\
\text { - Importance of CNT wetting by metals } \\
\text { - Interface chemistry with a range of metals } \\
\text { - Effects of oxidation } \\
\text { - Effects of external fields (magnetic, electric, strain, temp) } \\
\text { Experimental confirmation of models: } \\
\text { - Understand (theory) of UCC plus proof (experiment) } \\
\text { - Enable theoretical understanding to guide experiments }\end{array}$ & 11 & Modeling \\
\hline Establish standard measurement protocols for validation & 6 & \multirow{4}{*}{ Testing } \\
\hline Decouple work on electrical conductivity and ampacity & & \\
\hline Investigate $\mathrm{AC}$ in addition to $\mathrm{DC}$ & & \\
\hline Methods to characterize the distribution of CNTs in the material & & \\
\hline Explore process "design space" and sensitivity to perturbations & 1 & \multirow{3}{*}{ Processing } \\
\hline Scale up to make process economically feasible & & \\
\hline UCC's performance in downstream processes & & \\
\hline $\begin{array}{l}\text { Quantify "value" of UCC in relevant applications to guide setting of } \\
\text { performance targets }\end{array}$ & 6 & $\begin{array}{c}\text { Value } \\
\text { Proposition }\end{array}$ \\
\hline Collaboration / sharing: Need a structure to encourage / enable & & Collaboration \\
\hline Need championed effort by federal agency if USA is to win & 3 & Outreach \\
\hline
\end{tabular}

experimental sets. While significantly more difficult to develop than empirical models, first principlesbased models commence directly at the level of established science and do not make assumptions or use fitting parameters. These models calculate physical quantities without input parameters or a minimal set, and can give an approximation of the true state of the system. Consequently, successful first principles models will provide an accurate initial estimation from which inferences can be made for physical applications. More importantly, the breadth of applicability imparted through the number of included parameters is only limited by the diligent and ingenuity of the model developer. Ultimately, successful first principles models will provide significant understanding and insights into the basic characteristics of materials or systems.

The challenge of determining bulk or effective properties of composites is a classical problem. Typically, the microscopic length scale (e.g. domains in a composite network) is much larger than the atomic dimensions so that the domains possess apparent macroscopic properties. At the same time, these microscopic features are significantly smaller than the characteristic length of the macroscopic sample. In such instances, the composite can be viewed as a continuum on the microscopic scale such that macroscopic or bulk properties can be ascribed. Because bulk properties are sensitive to composite microstructure, an effective approach is to model the composite by considering its microstructure (or nanostructure in this case) such that changes in micro-/nanostructure can be quantitatively related to variations in macroscopic parameters. 
Compared to metal-matrix nanocomposites, there have been more attempts in developing models to describe electrical conductivity in polymer-CNT conductive nanocomposites, perhaps because they are comparatively easier to make for validation purpose. For example, Aneli et al. [22] performed a review on conductive polymer composites by considering different conceptions on conductivity and mechanisms of charge transfer in composite media. They showed that frequently experimental results are only partially in agreement with existing theoretical models. It was suggested that various physical and chemical factors that can affect the formation process of electrical current are missing from these models, and is a major reason for the discrepancies. Safdari [23] developed a model to quantify the electrical conductivity of a multiphase polymer-CNT-graphite nanoplatelet (GNP) nanocomposite by arguing that quantum tunneling is the major mechanism for charge carrier transport. The model predicts the effective conductivity through estimating the critical distance, which is a geometrical parameter that represents the averaged inter-particle distance. Comparison with experimental data showed that the model successfully predicted the effective conductivity for low CNT/GNP contents. For higher contents, the model only suggested the trend. On the other hand, Feng [24] developed a mixed micromechanics model that incorporated nanoscale electron hopping and micro-scale conductive network to predict the effective electrical conductivity of polymer-CNT nanocomposites. His model showed that while both electron hopping and conductive networks are operative, the networks are found to dominate the bulk electric conductivity after percolation. In addition, sizes of the CNTs have major effects on the percolation threshold and hence the overall electrical conductivity. Furthermore, by incorporating stretching (i.e. strain) induced changes into the model, it was determined that stretching the nanocomposite will decrease its electrical conductivity along the stretch direction, with greater effect on nanocomposites with lower volume fraction of CNT. Importance of deformation has also been considered by others. Using a revised 3-D percolating network model, Gong et al. [25] have studied the effect of CNT deformation on the electrical conductivity of polymer-CNT nanocomposites at crossed nanotube junctions. Based on electron ballistic tunneling theory and Landauer-Büttiker formula, they described the different CNT-CNT contact resistances at the CNTCNT junctions in terms of local deformation of CNT walls and CNT-CNT distances. Monte Carlo simulations were then used to evaluate these effects on electrical conductivity for nanocomposites with various CNT contents. Their results showed that local deformation of CNT walls has significant effect on electrical conductivity; intrinsic resistance of deformed portion of CNTs near a CNT-CNT junction increases much faster than the decrease in CNT-CNT contact resistance at the same junction as the two CNTs become closer. The net result is an increase in junction resistance. The implication is that models that do not consider CNT deformation may overestimate the conductivity of nanocomposites containing homogeneous distribution of CNTs within the percolating network.

In comparison, the amount of effort to model metal-CNT nanocomposites, and UCC specifically, has been relatively small. He et al. [26] considered the case of UCC nanowire as nano-scale interconnects for microelectronics application. As the nanowire dimensions are reduced to that of electron mean free path and ballistic conductivity takes effect, the electrical conductance of the nanowire would become independent of its length. They studied the transport properties of UCC nanowires under the influence of electric fields using density function theory, and found that the amount of quantum conduction of a nonhelical atomic strand decreases with increasing electric field. In contrast, opposite effect was found for a helical atomic strand. Moreover, these changes are affected by changes in atomic layer distance of the nanowire and the electronic distribute along their axis. In another effort based on density functional theory combined with non-equilibrium Green functions, Yang [27] studied the influence copper has on the electronic structure and metallic/semiconducting states of CNT. His results showed that both the density of state and the transmission coefficient of a $\mathrm{CNT} / \mathrm{Cu}$ system were increased. In addition, the bandgap was decreased leading to enhanced conductivity. Moreover, filling copper chains into CNT has led to a transition from semiconducting to metallic state. Similarly, absorption of copper chains onto CNT has the same effect but less efficiently. 
Considering the degree to which modeling will enhance the foundational understanding of UCC and its potential impact on accelerating the development of practical conductors, it is the consensus of meeting attendees that first principles modeling of UCC is the top research priority. Many factors can and should be considered in the models. These include CNT atomic structures (SWCNT, DWCNT, MWCNT), CNT chirality, CNT dimensions, CNT defects and impurities, CNT-CNT junctions, effects of CNT surface functionalization, CNT-copper interfaces (ends, cylindrical surfaces) and interfacial chemistry, CNTcopper interactions, copper diffusion/electromigration, UCC morphology (inter-CNT spacing, CNT content, distribution and alignment, inhomogeneity, percolation networks), effects of external fields (magnetic, electric, strain, temperature), etc.

Usefulness of any given model is dependent on its accuracy and efficiency in describing or predicting the responses of a system under consideration. By extension, efforts should also be made to validate the models, as they are being developed, through experimental observations and measurements. Experimental verification can be accomplished via two approaches. One approach is by thoroughly examining the physical, chemical and micro-/nano-structural characteristics of selected regions of UCC samples. This will require the selection of appropriate techniques and the development of standardized measurement protocols agreed upon by the research

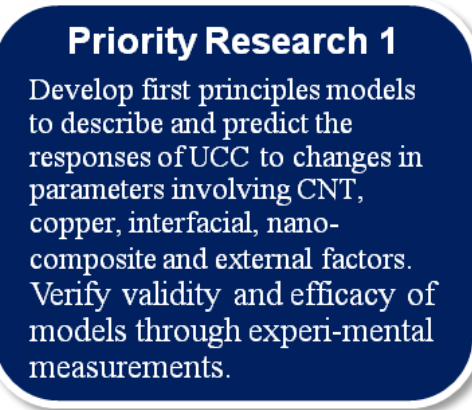
community. Another approach is to fabricate "model" samples specifically prepared to isolate certain parameters that are being considered. While the processing to create such modeled samples will be difficult and complex, the results they can provide will be unambiguous. Appropriate experimental techniques and measurement protocols will need to be followed as well.

\subsection{PRIORITY RESEARCH 2: STANDARDIZE MEASUREMENT PROTOCOLS}

For any emerging technology, extraordinary claims require convincing proofs. UCC suffers from a certain amount of credibility gap for a variety of reasons. There is little to no collaboration between researchers so that results of enhanced electrical conductivity are not verified by partners. There is limited information in open literature such that third parties cannot reproduce the results. Even when samples are supplied to partners, the measured results are frequently not duplicated. Most importantly, there is no standardized protocol to measure the most important transport and micro-/nano-structural characteristics that are so important to the health of UCC research, development and commercialization.

Take, for example, the seemingly easy task of determining the conductivity or resistivity of a conductor. The classic approach is to use a four-probe measurement arrangement where the outer probes supply the prescribed current $(I)$ and the inner probes measure the voltage $(V)$ drop. Current-voltage $(I-V)$ curve of the sample can thus be obtained, and resistivity can be determined from ohms law knowing the separation distance between the voltage taps and the cross sectional area of the sample.

Simply following this procedure, however, does not guarantee that the measurement will be reproducible, especially among different institutions where experimental details can vary significantly. For example, temperature of the region being measured can vary due to resistive heating or thermal propagation depending on the contact resistance at current injection site, whether continuous or pulsed current is being used, and the duration of current injection. The question of whether the $I-V$ curve is linear (at various temperatures) will complicate the matter, especially if voltage is only being measured at one current value to save time. Lastly, accuracy in measuring the sample dimensions will have huge impact on the 


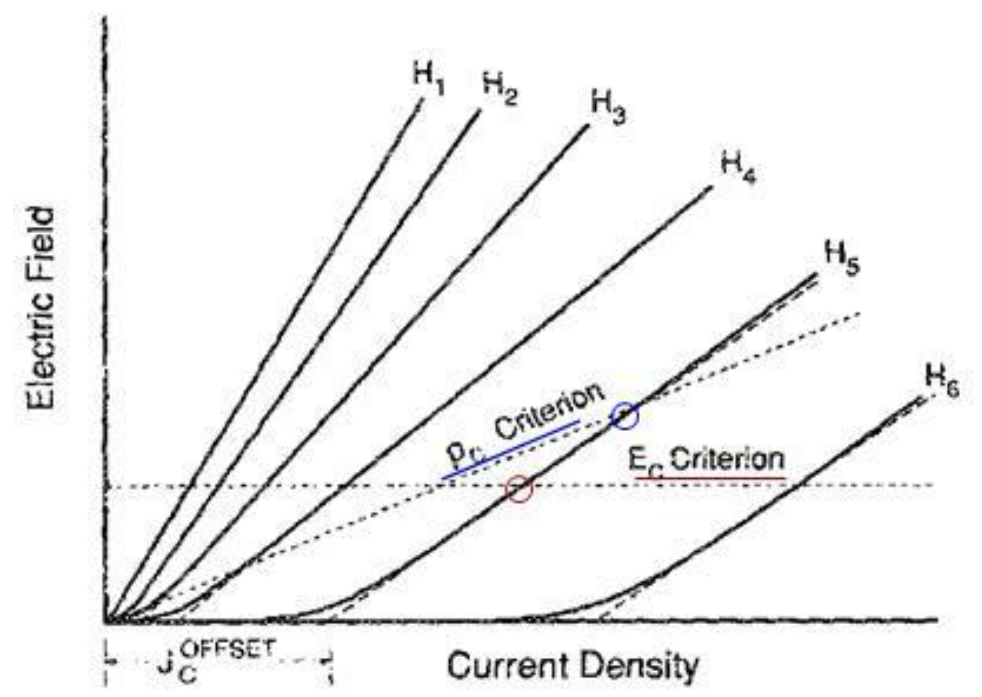

Fig. 13. Schematic electric field - current density curves of a superconductor at different magnetic fields. Also shown are the electric field $E_{c}$ and resistivity $\rho_{c}$ criteria that are used to determine critical current density [28].

calculated resistivity. This is particularly significant for UCC since the presently available samples are typically small and frequently with irregular cross sections.

It is therefore evident that development of standardized measurement protocol for the determination of UCC conductivity is a top priority. This need for standardization is not new; researchers in high temperature superconductivity (HTS) had to develop protocols to measure critical current density even though superconductivity has been known for more than a century. This difficulty is illustrated in Fig. 13 where schematic electric field-current density $(E-J)$ curves of a HTS are plotted for different magnetic fields [28]. Because of the gradual changes in the $E-J$ curves, critical current density determination can be problematic. Classic electric field criterion (horizontal dashed line labeled $E_{c}$ ) and resistivity criterion (sloped, dashed line going through the origin and labeled $\rho_{c}$ ) are shown in the figure. Critical current is defined as the current at which the $E$ - $J$ curves intersect the respective criterion line (red and blue circles at $H_{5}$ for $E_{c}$ and $\rho_{c}$ criteria, respectively). Thus, different critical current densities will result depending on which criterion is used. Furthermore, both criteria suffer from the fact that the critical current density will depend strongly on the criterion values being used. That is, critical current density should be a material property and not dependent on measurement techniques. These discrepancies led to the adoption of an electric field offset criterion, where a tangent is applied to the $E$ - $J$ curve at an agreed upon electric field value (typically10 $\mu \mathrm{V} / \mathrm{cm}$ ) and critical current density is where the tangent extrapolates to zero electric field.

In order to alleviate these types of concerns and maximize the consistency of measurements made at different institutions, the meeting participants strongly endorse efforts to develop and standardize conductivity/resistivity measurement protocol. These may include methods to ensure that sample cross section is uniform along the region to be measured, technique to apply contacts, type of current (DC, AC, continuous, pulsed, duration) and criterion to be used. In addition to ambient temperature, conductivity/ resistivity should also be measured at other temperatures that are relevant to practical applications. Standardized temperatures should be selected, and methods and protocols should be developed to ensure temperature stability. 
While conductivity is the indicator for electrical transport property of the material, ampacity provides the guidance for conductor operation in power applications. Also known as current carrying capability or current rating, ampacity (short for ampere capacity) is the maximum amount of electric current a conductor can carry before suffering from immediate or progressive degradation. It designates the value of current a conductor can carry continuously while remaining within its temperature rating. Ampacity of a conductor depends on a number of factors including the resistivity of the material, its insulation temperature rating, heat dissipation characteristics, temperature and current frequency. Although true ampacity is based on physical and electrical properties of the material as well as other conductor- and environment-specific factors, the group nevertheless feels that information on (quasi-) ampacity of UCC will be helpful in understanding its electrical and thermal transport as well as potentials for power applications. Ampacity measurement protocols including method, temperatures and currents and degradation criteria should be developed for UCC.

In addition to protocols for electrical properties, standardized techniques and protocols should also be developed to efficiently measure other important characteristics such as CNT dimensions, dispersion, distribution, alignment, CNT-copper interface structures and chemistry, etc. Efforts should also be made to attempt roundrobin testing amongst UCC researchers to identify discrepancies and potential deficiencies. Finally, the possibility of utilizing a neutral and reputable third party such as a national lab to verify testing results for all stakeholders should be explored.

\section{Priority Research 2}

Develop standardized

measurement techniques and protocols to ensure the validity, accuracy and acceptance of UCC results

\subsection{PRIORITY RESEARCH 3: TECHNO-ECONOMIC ANALYSES}

Researchers want guidance so that their work will solve the most impactful and valuable problems and final likely commercial applications for UCC. Although they understand that wire is the most common form in which conductive metals are currently used, they lack a clear knowledge of the value and marketentry-timing of possible target applications (eg. aerospace wiring, distribution wiring, transformers, motors, data wiring). Providing value to customers is a major factor that will determine whether a product will be broadly adopted and achieves commercial success. Having a lower cost and better cost/performance ratio are only the starting points in understanding the value proposition of a technology. Frequently, the true value of a technology is revealed when the technology, balance of system, operation and maintenance costs and other soft costs are analyzed in totality, even if the technology itself is more costly.

Consider the case of the so-called high temperature low sag (HTLS) conductors. These conductors are a class of ambient temperature overhead power lines that are designed to operate at higher temperatures by allowing increased current flow but without excessive sagging that could lead to shorting and faults. This is typically accomplished through the inclusion of a high strength and high stiffness inner core. 3M's Aluminum Conductor Composite Reinforced (ACCR) and CTC Global's Aluminum Conductor Composite Core (ACCC) cables are examples of HTLS conductors. Due to the combination of a reinforced core and low resistivity outer aluminum strands, HTLS conductors typically possess smaller thermal expansion for less sag, equivalent strength and durability, and lower weight when compared to conventional Aluminum Conductor Steel Reinforced (ACSR) and Aluminum Conductor Steel Supported.(ACSS) cables. These favorable characteristics allow HTLS conductors to offer a combination of attractive options such as:

- Carrying $2 \mathrm{X}$ more power by operating at higher temperatures (e.g. $210^{\circ} \mathrm{C}$ vs. $75^{\circ} \mathrm{C}$ for $\mathrm{ACSR}$ ) under continuous normal operation conditions; 
- Increasing distance between transmission towers, thereby reducing initial capital cost;

- Increasing ampacity over existing rights-of-way and easier permitting, etc.

Table 3 [29] shows the total project costs per line mile of upgrading a transmission line using conventional ACSS conductor vs. 3M ACCR HTLS conductor, broken down into the various project components. It can be seen from the table that by eliminating the need for new towers, land acquisitions and other factors, upgrading with ACCR is more economical, even though the HTLS conductor costs more per line mile.

Table 3.3M HTLS ACCR upgrade cost comparison example (project cost per line mile) [29]

\begin{tabular}{|c|c|c|c|}
\hline & $\begin{array}{l}\text { Build Parallel } \\
\text { Double Circuit } \\
\text { Line with A CSS }\end{array}$ & $\begin{array}{l}\text { Upgrade to Double } \\
\text { Circuit, Double } \\
\text { Bundled with ACSS }\end{array}$ & $\begin{array}{l}\text { Upgrade to } \\
\text { Double Circuit } \\
\text { with 3M ACCR }\end{array}$ \\
\hline Conductor ${ }^{1}$ & $\$ 126,000$ & $\$ 234,000$ & $\$ 584,000$ \\
\hline Stringing & $\$ 126,000$ & $\$ 251,000$ & $\$ 126,000$ \\
\hline Structures 2 & $\$ 1,150,000$ & $\$ 916,000$ & $\$ 81,000$ \\
\hline Substation Work & $\$ 335,000$ & $\$ 108,000$ & $\$ 0$ \\
\hline Development ${ }^{3}$ & $\$ 357,000$ & $\$ 287,000$ & $\$ 108,000$ \\
\hline Total & $\$ 1,796,000$ & $\$ 1,796,000$ & $\$ 899,000$ \\
\hline Construction Time & 2 to 5 years & Up to 2 years & $\begin{array}{l}4 \text { months during } \\
\text { low demand periods }\end{array}$ \\
\hline $\begin{array}{l}\text { Cost Savings of } \\
\text { 3M ACCR }\end{array}$ & $\$ 1,197,605$ & \$ 898,204 & - \\
\hline $\begin{array}{l}\text { Based on costs from I } \\
1 \text { Includes conductor } \\
2 \text { Includes structures, } \\
3 \text { All costs up to start }\end{array}$ & $\begin{array}{l}\text { tility projects and repres } \\
\text { installation accessories. } \\
\text { dations and labor. }\end{array}$ & ts U.S. costs only. & \\
\hline
\end{tabular}

In order to assess the potential impacts of UCC and its value propositions to prospective sponsors and industry partners, the meeting participants recommend the techno-economic analyses of UCC for relevant applications as a priority research activity. The analyses should include the costs of manufacturing based on promising scalable processing methods. Different performance levels should be analyzed against manufacturing costs for each relevant application so that performance targets can be

Priority Research 3

Perform techno-economic analyses of UCC for relevant applications to establish value propositions.

set to guide the development of different UCC variance. Savings and benefits should be quantified for each application, and compared to appropriate competing technologies. Intangibles such as enabling factors (e.g. lighter generators for higher power offshore wind turbines), environmental impacts (e.g. greenhouse gas emission), public sentiment (e.g. new transmission corridors, aesthetics), etc. should also be considered. 


\section{SUMMARY}

Ultraconductive copper is an emerging technology that has the potential to transform the energy sector with high capacity power lines, lighter electric vehicles, more energy-dense wind turbines, etc. Significant progress has been made in the development of this new nanocomposite material, with tantalizing results on enhanced electrical conductivity, higher mechanical strength, and better characteristics for thermal management. Unfortunately, these exceptional results are frequently tempered by non-uniformity, unpredictability or non-reproducibility due to unstable manufacturing processes. These uncertainties, coupled with lack of understanding in how different factors will fundamentally affect UCC performance as well as competing interests amongst researchers and developers combined to prevent the rapid development of UCC into practical conductors.

In light of these concerns, a UCC Strategy Meeting was held to identify and prioritize non-proprietary research activities that will improve the foundational understanding of UCC and accelerate its development. Many activities were suggested, and the followings represent the top three consensus priority research activities:

1) Modeling of UCC material to obtain foundational understanding in its operation;

2) Develop standardized measurement protocols to assure validity and credibility of data;

3) Perform techno-economic analyses to quantify value propositions and set performance targets for relevant applications. 


\section{REFERENCES}

1. O. Hjortstam, P. Isberg, P. Soderholm and H. Dai, "Can We Achieve Ultra-Low Resistivity in Carbon Nanotubes-Based Composites?” Appl. Phys. A 78, 1175 (2004).

2. Quanfang Chen, “Carbon Nanotube Reinforced Metal Composites”, US Patent No. 7,651,766 B2, 26 January, 2010.

3. Randall Reagan Buckner, Kyle Ryan Kissell, Howard Scott Horton and Clayton Charles Gallaway, "Conductive Metal Enhanced with Conductive Nanomaterial", World Patent WO 2013/072687 A2, 23 May, 2013.

4. S. Belgamwar and N.N. Sharma, "Method of Producing Uniform Mixture of Copper and Carbon Nanotube in Bulk for Copper Metal Nanocomposite", Indian patent application 2454/DEL/2012.

5. Taysir H. Nayfeh and Anita M. Wiederholt, "Nano-Engineered Ultra-Conductive Nanocomposite Copper Wire,” US Patent Application No. 2012/0152480 A1, 21 June, 2012.

6. Terry Holesinger, "Development of Carbon Nanotube Composite Cables for Ultra-Deepwater Oil and Gas Fields", a RPSEA Phase I Final Report August 1, 2012, https://www.netl.doe.gov/file\%20library/research/oil-gas/deepwater\%20technology/09121-330010-phase1-final-report.pdf

Terry G. Holesinger, "Carbon Nanotube Composite Conductors", World Patent WO 2014/189549 A2, 27 November, 2014.

7. James Maxwell et al. "Ultraconductus: Innovative Electrical Conductors," http://www.lanl.gov/science/NSS/issue2_2011/story5full.shtml

8. Nobuya Banno and Takao Takeuchi, "Enhancement of Electrical Conductivity of Copper/Carbon Nanotube Composite Wire", J. Japan Inst. Metals, 73(9), 651 (2009).

9. “Ultrawire: Ultra Conductive Copper-Carbon Nanotube Wire," http://ultrawire.eu/ http://cordis.europa.eu/projects/rcn/108893_en.html

10. Subramaniam et al, "One hundredfold increase in current carrying capacity in a carbon nanotubecopper composite", Nature Communications, DOI:10.1038/ncomms3202, July 2013.

11. Marc Bockrath, David H. Cobden, Jia Lu, Andrew G. Rinzler, Richard E. Smalley, Leon Balents and Paul L. McEuen, "Luttinger-Liquid Behavior in Carbon Nanotubes", Nature 397, 598 (1999),

12. Henk W.Ch. Postma, Mark de Jonge, Zhen Yao, and Cees Dekker, "Electrical Transport Through Carbon Nanotube Junctions Created by Mechanical Manipulation”, Phys. Rev. B 62(16), 10653 (2000).

13. A. Calusaru, in Electrodeposition of Powders from Solutions, Elsevier, New York, 1979.

14. Antonioni C. Stevens et al, "System and Method for Producing Copper Powder by Electrowinning in a Flow-Through Electrowinning Cell”, US patent number 7,378,010 B2, 27 May, 2008.

15. "Metal / Carbon nanotube Composites," Fraunhofer Institute for Manufacturing Technology and Advanced Materials IFAM Dresden http://www.ifam.fraunhofer.de/content/dam/ifam/en/documents/dd/Infobl\%C3\%A4tter/metalcarbon_nanotube_composites_fraunhofer_ifam_dresden.pdf 
16. Kazuaki Katagiri, Atsushi Kakitsuji, Toyohiro Sato and Terumitsu Imanishi, "Method for Producing Carbon Nanotube-Dispersed Composite Material", US Patent application number 20070057415 , March 15, 2007.

17. Katsuyoshi Kondoh and Bunshi Fugetsu, "Composite Metal Material and Method for Producing the Same”, US Patent application number 20100261028, October 14, 2010.

18. D. Nunes et al, "Consolidation of Cu-Diamond Nanocomposites: Hot Extrusion vs. Spark Plasma Sintering”, Materials Science Forum 636-637, 682 (2010).

19. J.B. Forsyth and C.R. Fletcher, "Apparatus for Producing Wire Bars by Electrodeposition," US Patent number 570,125, Oct 27, 1896.

20. Sidney J. Clouser et al, "Copper wire and process for making copper wire", US patent number 6,123,788, September 26, 2000.

21. Natnael Behabtu et al, "Strong, Light, Multifunctional Fibers of Carbon Nanotubes with Ultrahigh Conductivity”, Science 339(6116), 182 (2013).

22. Jimsher Aneli, Gennady Zaikov and Omar Mukbaniani, "Physical Principles of the Conductivity of Electrical Conducting Polymer Composites (Review)," Chemistry \& Chemical Technology 5(1), 75 (2011).

23. Masoud Safdari, "A Computational and Experimental Study on the Electrical and Thermal Properties of Hybrid Nanocomposites based on Carbon Nanotubes and Graphite Nanoplatelets," (2012). Virginia Polytechnic Institute and State University. Ph.D. Dissertation. https://vtechworks.lib.vt.edu/bitstream/handle/10919/49570/Safdari_M_D_2012.pdf?sequence=1

24. Chuang Feng, "Micromechanics Modeling of the Electrical Conductivity of Carbon Nanotude (CNT)- Polymer Nanocomposites" (2014). University of Western Ontario - Electronic Thesis and Dissertation Repository. Paper 2197.

http://ir.lib.uwo.ca/cgi/viewcontent.cgi?article $=3705 \&$ context=etd

25. S. Gong, Z.H. Zhu and E.I. Haddad, "Modeling Electrical Conductivity of Nanocomposites by Considering Carbon Nanotube Deformation at Nanotube Junctions," J. Appl. Phys. 114 (7), 074303 (2013).

26. C. He, P. Zhang, Y. F. Zhu, and Q. Jiang, "Structures and Quantum Conduction of Copper Nanowires under Electric Fields Using First Principles,” J. Phys. Chem. C 112, 9045 (2008).

27. Chengyu Yang, "First Principle Studies of $\mathrm{Cu}$-Carbon Nanotube Hybrid Structures with Emphasis on the Electronic Structures and the Transport Properties," (2013). University of Central Florida. Ph.D. Dissertation. http://etd.fcla.edu/CF/CFE0005280/Dissertation-rev1.3.pdf

28. J.W. Ekin, "Offset Criterion for Determining Superconductor Critical Current," Appl. Phys. Lett. 55(9), 905 (1989).

29. $3 \mathrm{M}^{\mathrm{TM}}$ Aluminum Conductor Composite Reinforced (ACCR) High-capacity transmission conductor - Netric Units

http://multimedia.3m.com/mws/mediawebserver?mwsId=SSSSSuH8gc7nZxtUNYtSn8_BevUqe17 zHvTSevTSeSSSSSS--\&fn=ACCR_CombinedMetric_2014_Celum_8

30. NanoRidge Materials Inc., Private communications. 
APPENDIX A. UCC STRATEGY MEETING LIST OF PARTICIPANTS 



\section{APPENDIX A. UCC STRATEGY MEETING LIST OF PARTICIPANTS}

Arnold, Cheryl

Manager, Federal Advocacy Practice

LNE Group

carnold@lnegroup.com

Burwell, Malcolm

Director, North America

Technology Development \& Transfer

International Copper Association

malcolm.burwell@copperalliance.org

Chen, Quanfang

Professor

Materials Science \& Engineering Dept

University of Central Florida

Quanfang.Chen@ucf.edu

Haught, Debbie

Program Manager

Office of Electricity Delivery and Energy Reliability

U.S. Department of Energy

Debbie.Haught@hq.doe.gov

Hummelt, Edward

Principal Engineer

Eaton Corporation

EdwardJHummelt@eaton.com

Kissell, Kyle

Director

Technology Development

NanoRidge Materials Inc.

kkissell@nanoridge.com

Kraft, Frank

Professor and Director

Center for Advanced Materials Processing

Department of Mechanical Engineering

Ohio University

kraftf@ohio.edu
Lee, Dominic

Program Manager

Energy Efficiency and Electricity Technologies

Office

Oak Ridge National Laboratory

leedf@ornl.gov

Mehta, Rajesh

Program Director

SBIR/STTR Programs

National Science Foundation

rmehta@nsf.gov

Strubbe, David

Post-Doctoral Fellow

Materials Science and Engineering Dept

Massachusetts Institute of Technology

dstrubbe@mit.edu

Vlassiouk, Ivan

Research Staff Member

Nanosystems, Separations, \& Materials Research

Group

Oak Ridge National Laboratory

vlassioukiv@ornl.gov

Remote Participants:

Nayfeh, Taysir

Professor and Director

Industrial Space Systems Lab

Department of Mechanical Engineering

Cleveland State University

t.nayfeh@csuohio.edu

Wiederholt, Anita

Post-graduate student

Industrial Space Systems Lab

Department of Mechanical Engineering

Cleveland State University

a.wiederholt@gmail.com 
End of Report 